\title{
Endotoxin levels in Estonian and Swedish house dust and atopy in infancy
}

Malin Böttcher (Fagerås), Bengt Björkstén, Sofia Gustafson, T. Voor and Maria C. Jenmalm

\section{Linköping University Post Print}

\section{Tweet}

N.B.: When citing this work, cite the original article.

This is the pre-reviewed version of the following article:

Malin Böttcher (Fagerås), Bengt Björkstén, Sofia Gustafson, T. Voor and Maria C. Jenmalm, Endotoxin levels in Estonian and Swedish house dust and atopy in infancy, 2003, Clinical and Experimental Allergy, (33), 3, 295-300.

which has been published in final form at:

http://dx.doi.org/10.1046/j.1365-2222.2003.01562.x

Copyright: Wiley-Blackwell http://eu.wiley.com/WileyCDA/Brand/id-35.html

Postprint available at: Linköping University Electronic Press http://urn.kb.se/resolve?urn=urn:nbn:se:liu:diva-13204 


\title{
Endotoxin levels in Estonian and Swedish house dust and atopy in infancy
}

\author{
Malin F Böttcher \\ Bengt Björkstén \\ Sara Gustafson \\ Tiia Voor* \\ Maria C Jenmalm
}

Department of Molecular and Clinical Medicine, Division of Paediatrics, and Clinical Research Centre, Faculty of Health Sciences, Linköping University, Sweden *Children's Clinic of Tartu University Clinics, Tartu, Estonia

Running title: Endotoxin and development of atopic disease 


\section{Abstract}

Background: Immune responses, including those to allergens, may be Th2 skewed in new-borns. In order to redress the foetal Th1/Th2 imbalance, Th1 stimulating factors, such as bacterial endotoxin, may be required. The increasing prevalence and severity of atopic diseases in industrialised countries, which are in marked contrast with the low prevalence of allergy among children in the formerly socialist countries of Europe, have been suggested to be caused by a reduced microbial stimulation.

Aim: To relate the endotoxin levels in house dust from two countries with a low (Estonia) and a high (Sweden) prevalence of allergy to the development of atopic disease and sensitisation in the children during the first two years of life.

Methods: The study included 108 children from Tartu, Estonia and 111 children from Linköping, Sweden. Skin prick tests were performed at 3, 6, 12 and 24 months of age, and questionnaires were distributed to the families. At 24 months, a paediatrician examined the children. Dust samples were collected from mattresses and carpets and the endotoxin concentration was determined by a chromogenic Limulus assay.

Results: The endotoxin levels were higher in Estonian than in Swedish house dust (median levels 29 (range 0.25-280) and 14 (range 0.25-99) EU/mg dust, respectively, $\mathrm{p}<0.001)$. Furthermore, the levels were inversely related to the development of atopic disease and sensitisation in the Swedish, but not in the Estonian, children.

Conclusions: The low prevalence of atopic disease in Estonia may, at least in part, be related to the high endotoxin levels in this country. The findings support that high levels of endotoxin, or other bacterial products with Th1-stimulating properties, might protect children from developing atopic disease.

Key words: Endotoxin, atopy, childhood 


\section{Abbreviations}

EU endotoxin units

IFN- $\gamma$ interferon- $\gamma$

Ig immunoglobulin

IL interleukin

LAL Limulus amebocyte lysate

OD optical densities

Th Thelper 


\section{Introduction}

Immune responses, including those to allergens [1], may be Th2 skewed in newborns $[2,3]$. Interleukin-12 [4] and IFN- $\alpha[5]$, produced by microbially stimulated antigen presenting cells, are the major inducers of $\mathrm{T}$ cell IFN- $\gamma$ production. Th1 stimulating factors, e $g$ from microbes, may be needed to redress and regulate the foetal Th1/Th2 imbalance.

The prevalence and severity of atopic diseases have increased in industrialised countries during the last decades [6-8]. Factors associated with a Western life style, $e$ $g$ a decreased overall exposure to microbial stimulation [9], may be associated with this increase, as several studies show a low prevalence of allergy among children in the formerly socialist countries of Europe with a life style similar to that prevailing in Western Europe 30-40 years ago [10-12].

Certain environments may provide heavy continuous external microbial exposure for redressing the foetal Th1/Th2 imbalance. Studies from Switzerland [13], Austria [14], Finland [15], Germany [16] and Canada [17] show that living on a farm during early childhood, particularly during the first year of life [18], is associated with a reduced prevalence of atopic disease. Among farmers' children, regular contact to livestock and poultry decreased the risk of atopic disease. Higher levels of IL-12 inducing endotoxin, the lipopolysaccharide component of the outer membrane of gram negative bacteria [19], were found in house dust from farming families than from non-farming families [20]. Thus, it was hypothesised that exposure to endotoxin during early life may stimulate the Th1 maturation and thus protect against the development of atopic disease [16]. In a recent rat study, endotoxin inhalation during primary allergen exposure in the presence of a Th2 promoting adjuvant prevented 
allergic sensitisation, whereas inhalation of endotoxin after sensitisation had occurred aggravated the inflammatory airway responses [21]. Furthermore, the negative association between development of atopic disease and early childhood exposure to pets shown in retrospective [22-24] and prospective [25] studies, has been suggested to be caused by increased microbial exposure secondary to pet keeping exposure rather than high dose tolerance induction. Interestingly, a recent cross-sectional study showed that exposure to low levels of endotoxin in house dust was associated with skin prick test reactivity in wheezing American children from families with a low socio-economic status [26]. Furthermore, the risk of developing atopic eczema was lower during the first six months, but not during the first year, of life in German infants exposed to high endotoxin levels [27]. No skin prick test or IgE data were reported in that study, however.

The aim of this prospective study was to relate the endotoxin levels in house dust from two countries with a low (Estonia) and a high (Sweden) prevalence of allergy to the development of atopic disease and sensitisation in the children during the first two years of life. 


\section{Material and Methods}

Subjects

Pregnant women and their families were asked by the midwives of the maternity clinics in Tartu, Estonia, and in Linköping, Sweden, to participate in the study. One hundred and fifteen Estonian and 149 Swedish families agreed to participate. The Estonian children were born between February 1997 and June 1998, and the Swedish children between March 1996 and April 2000. Dust samples were collected from the homes of 108 Estonian and 111 Swedish infants. Skin prick tests (SPT) were performed on $215 / 219$ of the children when they were 3 or 6,12 and 24 months old, and a clinical examination regarding allergic manifestations was done at 24 months of age. Atopic dermatitis was defined as pruritic, chronic, or chronically relapsing non-infectious dermatitis with typical features and distribution. Asthma was defined as three or more episodes of bronchial obstruction, at least once verified by a physician. Allergic rhinoconjunctivitis was defined as rhinitis and conjunctivitis appearing at least twice after exposure to a particular allergen and not related to infection. Skin prick tests were done in duplicate on the volar aspects of the forearms with thawed egg white and fresh skimmed cow's milk (lipid concentration $0.5 \%$ ) at either 3 or 6 months. At 12 and 24 months, SPT were also performed with a standardised cat extract (Soluprick®, ALK, Hørsholm, Denmark) in Sweden and Estonia, and a standardised Dermatophagoides pteronyssinus extract (Soluprick ${ }^{\circ}$, ALK) in Estonia. Histamine hydrochloride $(10 \mathrm{mg} / \mathrm{ml})$ was used as a positive control, and albumin diluent was included as a negative control. The test was regarded as positive if the mean diameter was $\geq 3 \mathrm{~mm}$.

The atopic status of the parents was established by a typical clinical history ( $i e$ allergic rhinoconjunctivitis, allergic asthma, or flexural itchy dermatitis). 
The families completed questionnaires when the children were 3,6, 12, 18, and 24 months old. The questionnaires included questions regarding symptoms of allergy, infections, presence of pets at home, family size, dwelling space, damage due to damp and presence of fitted carpets.

Two dust samples were collected from each household, one from a carpet and one from the child's mattress. In Estonia, the samples were collected by study staff, as every home did not have a suitable vacuum cleaner. In Sweden, the parents collected the dust samples. Most of the dust was collected between September and April when the children were between 3 and 12 months of age, although fourteen of the samples were collected during the summer, however (data not shown). The endotoxin levels did not vary with season, however. A dust collector device, containing a $6 \mu \mathrm{m}$ pore size filter (ALK), was connected to a vacuum cleaner. The mattress, without sheets, and two $\mathrm{m}^{2}$ of the carpet was vacuum cleaned for four minutes. The filters were stored in clean plastic bags and kept in $-20^{\circ} \mathrm{C}$ until analysis.

\section{Endotoxin analysis}

All extractions and endotoxin analyses were done under sterile conditions in Sweden. The dust was extracted with vigorous shaking for two hours in pyrogenfree glass test tubes (Bio Whittaker, Walkersville, Maryland, USA) with pyrogen-free Limulus Amebocyte Lysate (LAL) water (1 mL/100 mg dust) (Bio Whittaker, Walkersville, Maryland, USA) with 0.05\% Tween-20 (Sigma-Aldrich, Stockholm, Sweden). After centrifugation, at $1000 \times \mathrm{g}$ for 10 minutes (Sigma 3E-1), the supernatants were stored in pyrogen-free test tubes at $-20^{\circ} \mathrm{C}$ until analysis. Each 
sample was divided into two aliquots to avoid repeated thawing, which decreases the endotoxin levels.

The endotoxin levels were analysed with the same lot of a chromogenic LAL assay (QCL-1000®, Bio Whittaker) according to the manufacturer's instructions. Briefly, 50 $\mu \mathrm{L}$ aliquots from diluted (1:1000-1:100 000) samples were added to Costar 3595 microtiter-plates (Corning Incorporated, Corning, NY, USA), and assayed with the LAL reagents. Optical density (OD) was measured at $405 \mathrm{~nm}$ with an ELISA reader (Anthos ht II, Labdesign, Täby, Sweden). The endotoxin concentrations were calculated by referring the ODs of the samples to the ODs of a two-fold diluted standard calibration curve (0.05-2.00 Endotoxin Units $(\mathrm{EU}) / \mathrm{ml})$, included in the kit. The lowest limit for quantitative determinations, for samples diluted 1:1000, was 50 $\mathrm{EU} / \mathrm{mL}$, corresponding to $0.50 \mathrm{EU} / \mathrm{mg}$ dust. Samples with levels below this limit were assigned the value $0.25 \mathrm{EU} / \mathrm{mg}$. The intraassay variability was lower than $9 \%$ and the interassay variability was lower than $25 \%$. The results were related to dust quantity and expressed as EU/mg dust.

To evaluate the influence of components from the dust on the analysis, known amounts $(0.4 \mathrm{EU} / \mathrm{ml})$ of endotoxin were added to some dust samples before analysis. In addition to the endogenous endotoxin, $100 \pm 28 \%$ of the exogenous endotoxin was detected if the samples were diluted 1:1000 or more.

\section{Allergen analyses}

The levels of cat (Fel d 1), dog (Can f 1) and Dermatophagoides farinae (Der f 1) allergens were analysed by ELISA according to the instructions of the manufacturer (Indoor Biotechnologies, Cardiff, UK). All allergen analyses were done in Estonia. 
The lowest limit for quantitative determinations was $4 \mathrm{ng} / \mathrm{g}$ dust for Fel d 1, $10 \mathrm{ng} / \mathrm{g}$ dust for Can $\mathrm{f} 1$ and $4 \mathrm{ng} / \mathrm{g}$ dust for Der $\mathrm{f} 1$.

\section{Statistics}

As the endotoxin levels were not normally distributed, even after log transformation, paired analysis were performed with the Wilcoxon signed-rank test, unpaired analyses with Mann-Whitney U test, and correlations with Spearman's rank order correlation coefficient test. The chi-square test was employed for categorical variables. A probability level of $<0.05$ was considered to be statistically significant. The calculations were made with the statistical package StatView 5.0 for Macintosh (Abacus Concepts, Berkeley, CA, USA). Multivariate logistic regression was used to adjust for potential confounders using the statistical package Statistica 7.0 for PC (Statistica Corporation, College Station, TX, USA). The endotoxin levels were included as a continuous variable in the multivariate logistic regression model.

\section{Ethics}

The study was approved by the Regional Ethics Committee for Human Research at Linköping University and the Ethics Review Committee on Human Research of the University of Tartu. 


\section{Results}

Endotoxin was detected in almost all dust samples, i e 189/197 from mattresses and 196/201 from carpets. The median levels were $20.7 \mathrm{EU} / \mathrm{mg}$ dust (range 0.25-275) from mattress and 16.1 EU/mg dust (range 0.25-358) from carpet. The endotoxin levels in dust from mattress and carpet correlated ( $r h o=0.43, \mathrm{p}<0.001)$.

The levels of endotoxin were higher in dust from Estonian, as compared to Swedish, households, both in mattresses and carpets (fig 1). Pets at home and fitted carpets were more common in the Estonian than in the Swedish families (table 1). The families were larger in Estonia than in Sweden, while the dwelling space was smaller (table 1). This did not explain the differences in endotoxin levels between the two countries, however, as neither presence of pets, fitted carpets, nor family size were related to the endotoxin levels. Dwelling space was weakly inversely related to house dust endotoxin levels in mattress $(r h o=-0.20, \mathrm{p}<0.01)$ and in carpet $(r h o=-0.28$, $\mathrm{p}<0.001$ ). The correlation disappeared, when the levels in the two countries were analysed separately, however.

The Fel d 1, Can f 1 and Der f 1 levels were higher in Estonian than Swedish house dust, both in mattresses and carpets (table 2). Weak correlations were found between Fel $\mathrm{d} 1$ and endotoxin levels in mattresses $(r h o=0.21, \mathrm{p}=0.04$ in Sweden, $r h o=0.18$, $\mathrm{p}=0.08$ in Estonia), between Fel $\mathrm{d} 1$ and endotoxin levels in carpets ( $r h o=0.21, \mathrm{p}=0.03$ in Sweden, $r h o=0.20, \mathrm{p}=0.05$ in Estonia), and between Can $\mathrm{f} 1$ and endotoxin levels in carpets in Sweden ( $r h o=0.21, \mathrm{p}=0.03)$, but not in Estonia. No significant correlations were observed between Can f 1 and endotoxin levels in mattresses, and the Der f 1 and endotoxin levels did not correlate in any dust source. 
Skin test reactivity and allergic symptoms were more common among Swedish than Estonian children, and they also more often had atopic parents (table 1). Allergic symptoms were associated with low levels of endotoxin in dust from carpets $(p<0.01$, data not shown), but not from mattresses. The endotoxin levels were also lower in carpet dust from homes of skin prick test positive, as compared to negative, children $(\mathrm{p}<0.01$, data not shown). The inverse relationship between endotoxin levels and atopic disease (fig 2) and sensitisation was only observed in Sweden, and not in Estonia. Furthermore, the endotoxin levels were lower in carpet dust from Swedish families with atopic parents than in families lacking atopic heredity (median levels 10.3 EU/mg dust (range 0.25-47.7) and $19.1 \mathrm{EU} / \mathrm{mg}$ dust (range 1.4-90.1) respectively, $\mathrm{p}<0.001)$. The levels of endotoxin were still significantly lower in homes with a symptomatic than a healthy child, when adjusted for potential confounders, $i e$ atopic heredity, presence of pets, cat and dog allergen levels in dust, fitted carpets and damage due to damp, however (table 3). The odds ratio of 0.93 for endotoxin levels in relation to atopic symptoms was based on endotoxin levels as a continuous variable. Thus, for each unit the endotoxin levels increased, the risk for atopic symptoms decreased by $7 \%$. Employing $10 \mathrm{EU} / \mathrm{mg}$ intervals in the multivariate logistic regression model gave an odds ratio of $0.48(0.35-0.90)$. The association between low endotoxin levels and skin test reactivity in the Swedish children also persisted after adjusting for confounders (OR 0.95 (endotoxin levels were included as a continuous variable), 95\% CI 0.90-0.99, $\mathrm{p}=0.03$ ). In Estonia, atopic heredity and endotoxin levels were not associated. 


\section{Discussion}

The endotoxin levels were lower in house dust from Sweden than the formerly socialist country Estonia. These findings support that Western life style is associated with a decreased overall exposure to microbial stimulation. Whereas the prevalence and severity of atopic diseases have increased in industrialised countries during the last decades [6-8], epidemiological studies show a low prevalence of allergy among school children in Estonia [12], Eastern Germany [10] and other countries in central and Eastern Europe [11]. Furthermore, living on a farm in industrialised countries during early childhood is associated with a reduced prevalence of atopic disease [1317]. Such a life style may conceivably provide Th1 stimulating factors, $e g$ from microbes [20], to redress the foetal Th2 predominance [1-3].

Endotoxin, the lipopolysaccharide component of the outer membrane of gram negative bacteria, is one such Th1 inducing factor, through its capacity to induce high levels of IL-12 [19]. Induction of the anti-inflammatory cytokine IL-10 by endotoxin [28] may also protect against the development of atopic disease [29]. In the Swedish part of our prospective study, low endotoxin levels in carpets, but not in mattresses, were associated with atopic disease and sensitisation. The levels in carpets may reflect the general household endotoxin exposure better than the levels in mattresses. Our results support the hypothesis that exposure to endotoxin during early life may stimulate the maturation of the immune system and thus protect against the development of atopic disease. There was no difference in endotoxin levels between atopic and non-atopic children from Estonia, however. This may possibly depend on the generally high endotoxin levels in Estonia, providing a maximal effect, leaving room for the influence of other yet unknown environmental factors. 
The low endotoxin levels in Swedish families with atopic parents could lead to a false association between low endotoxin levels and atopic disease in the children. The differences in endotoxin levels between households with an atopic and a non-atopic child were still significant when adjusted for potential confounders, however. The reason for the low endotoxin levels in families with an atopic heredity could possibly be due to different cleaning habits or choice of dwelling.

The observed inverse relationship between atopy and endotoxin exposure may not be directly due to the exposure, but merely reflect less microbial stimulation in general. Other factors associated with such conditions, $i$ e Toxoplasma gondii and hepatitis A seropositivity, are also less common among atopic adults [30]. It has been suggested that the immune system needs to be educated by a diversified, persistent and continuously renewed microbial stimulation in order to function properly [31]. However, a direct effect of endotoxin on the allergic inflammation was recently observed in a rat model, showing that inhalation of endotoxin at the time of primary allergen exposure prevented IgE antibody formation, even in the presence of a Th2 promoting adjuvant [21]. Inhalation of endotoxin after sensitisation had occurred aggravated the inflammatory airway responses, however. Thus, while endotoxin exposure may augment an established allergic inflammation [32], it may have a protective influence on immune development prior to disease onset.

It has been suggested that the negative association between development of atopic disease and early childhood exposure to pets [22-25] could be due to increased microbial exposure rather than high dose tolerance induction. In our study, the endotoxin levels were similar in homes with and without pets, however, and the endotoxin and Fel d 1 and Can f 1 were only weakly correlated, in agreement with other reports [27]. 
In conclusion, this prospective study demonstrated an inverse relationship between endotoxin levels at home and development of atopic disease and sensitisation during the first two years of life in Swedish, but not Estonian, children. The low prevalence of atopic disease in Estonia may, at least in part, be related to the high endotoxin levels in this country. The findings support that high levels of endotoxin, or other bacterial products with Th1-stimulating properties, might protect children from developing atopic disease. 


\section{Acknowledgements}

We thank Kerstin Hagersten and Lena Lindell, Department of Health and Environment, Division of Paediatrics, Linköping University Hospital, Sweden, and Tiina Rebane, Children's Clinic of Tartu University Clinics, Tartu, Estonia, for excellent technical assistance, and Dr Mats Fredriksson, Department of Health and Environment, Division of Occupational Medicine, Linköping University Hospital, Sweden, for help with statistical analyses.

The Swedish Medical Research Council (grant \#7510), The Swedish Foundation for Health and Care Sciences and Allergy Research, The National Heart and Lung Association, Glaxo-Wellcome, The National Swedish Association against Allergic Diseases, The Samariten Foundation, Linköping University, The County Council of Östergötland and the First of May Flower Annual Campaign for Children's Health are acknowledged for financial support. 
Table 1. Characteristics of Estonian and Swedish children, who were followed prospectively for the first two years of life.

Five of the Estonian allergic children had atopic dermatitis only, one had atopic dermatitis and asthma, and three had asthma only. All 24 allergic Swedish children had atopic dermatitis, and five of them also had asthma.

Differences between the groups were compared with chi-square test for categorical variables, and with Mann-Whitney U-test for numerical variables.

*SPT and clinical data were missing from 4 Swedish children.

\begin{tabular}{|l|c|c|c|}
\hline & $\begin{array}{c}\text { Estonian } \\
(\mathrm{n}=108)\end{array}$ & $\begin{array}{c}\text { Swedish } \\
(\mathrm{n}=111)\end{array}$ & p-value \\
\hline $\begin{array}{l}\text { SPT positive (cumulative), } \\
\text { number (\%) }\end{array}$ & $15(14 \%)$ & $27(25 \%)^{*}$ & 0.03 \\
\hline $\begin{array}{l}\text { Allergic symptoms (cumulative), } \\
\text { number (\%) }\end{array}$ & $9(8 \%)$ & $25(24 \%)^{*}$ & $<0.01$ \\
\hline $\begin{array}{l}\text { Atopic heredity, } \\
\text { number }(\%)\end{array}$ & $29(27 \%)$ & $76(68 \%)$ & $<0.001$ \\
\hline $\begin{array}{l}\text { Dwelling space, } \\
\text { median and range } \\
\text { (m } / \text { family member) }\end{array}$ & $14.3(3.6-75)$ & $28.3(16.3-91.7)$ & $<0.001$ \\
\hline $\begin{array}{l}\text { Pets at home, } \\
\text { number }(\%)\end{array}$ & $42(39 \%)$ & $17(15 \%)$ & $<0.001$ \\
\hline $\begin{array}{l}\text { Presence of fitted carpet, } \\
\text { number }(\%)\end{array}$ & $32(30 \%)$ & $15(14 \%)$ & $<0.01$ \\
\hline $\begin{array}{l}\text { Number of family members, } \\
\text { median and range }\end{array}$ & $4(2-9)$ & $3(2-8)$ & 0.03 \\
\hline
\end{tabular}


Table 2. Allergen levels (\% positive samples and median (range) ( $\mu \mathrm{g} / \mathrm{g}$ dust)) in Estonian and Swedish mattress and carpet dust.

The Fel d 1, Can $\mathrm{f} 1$ and Der $\mathrm{f} 1$ levels were higher in Estonian than Swedish house dust, both in mattresses and carpets $(\mathrm{p}<0.001$ for all comparisons, Mann-Whitney $U$-test). $\mathrm{n} d$, not detectable.

\begin{tabular}{|c|c|c|c|}
\hline Allergen & Source & Estonia & Sweden \\
\hline \multirow[t]{2}{*}{ Fel d 1} & mattress & $\begin{array}{c}100 \% \\
1.20(0.06-598)\end{array}$ & $\begin{array}{c}97 \% \\
0.28(\mathrm{n} \mathrm{d}-106)\end{array}$ \\
\hline & carpet & $\begin{array}{c}100 \% \\
0.51(0.05-358)\end{array}$ & $\begin{array}{c}98 \% \\
0.16(\mathrm{nd}-172)\end{array}$ \\
\hline \multirow[t]{2}{*}{ Can f 1} & mattress & $\begin{array}{c}100 \% \\
0.89(0.06-92.7)\end{array}$ & $\begin{array}{c}98 \% \\
0.29(\mathrm{nd}-149)\end{array}$ \\
\hline & carpet & $\begin{array}{c}100 \% \\
0.75(0.02-592)\end{array}$ & $\begin{array}{c}97 \% \\
0.32(\mathrm{nd}-332)\end{array}$ \\
\hline \multirow[t]{2}{*}{ Der f 1} & mattress & $\begin{array}{c}100 \% \\
0.31(0.05-94.8)\end{array}$ & $\begin{array}{c}38 \% \\
\text { nd (n d - 0.41) }\end{array}$ \\
\hline & carpet & $\begin{array}{c}93 \% \\
0.07(\mathrm{n} \mathrm{d}-16.1)\end{array}$ & $\begin{array}{c}10 \% \\
\mathrm{nd}(\mathrm{nd}-0.11)\end{array}$ \\
\hline
\end{tabular}


Table 3. Multivariate relationship between the presence of atopic symptoms (atopic dermatitis or atopic dermatitis and asthma) in 2-year old Swedish children, and some possible risk or protective factors based on a multiple logistic regression analysis. Each estimated odds ratio was adjusted for the effect of all other exposure variables in the table. The endotoxin levels were included as a continuous variable in the multivariate logistic regression model.

\begin{tabular}{|c|ccc|}
\hline & Odds ratio & $\begin{array}{c}\text { Confidence } \\
\text { interval }\end{array}$ & p-value \\
\hline $\begin{array}{c}\text { Endotoxin levels } \\
\text { in carpet }\end{array}$ & 0.93 & $0.90-0.99$ & 0.02 \\
\hline $\begin{array}{c}\text { Atopic heredity } \\
\text { Pets at home }\end{array}$ & 2.60 & $0.62-10.94$ & 0.19 \\
\hline $\begin{array}{c}\text { Fel d 1 levels } \\
\text { in carpet }\end{array}$ & 2.05 & $0.47-8.99$ & 0.34 \\
& & & 0.49 \\
\hline $\begin{array}{c}\text { Fitted carpets } \\
\text { in carpet }\end{array}$ & 1.00 & 1.00 & 0.12 \\
\hline
\end{tabular}




\section{Legends to figures}

Fig 1. Endotoxin levels in dust from Estonian and Swedish households.

Higher endotoxin levels, expressed as endotoxin units (EU) per mg dust, were found in house dust from Estonian (Est) than in Swedish (Swe) homes. The $10^{\text {th }}, 25^{\text {th }}, 50^{\text {th }}$, $75^{\text {th }}$ and $90^{\text {th }}$ percentiles are indicated, as well as outliers.

Fig 2. Endotoxin levels in Estonian and Swedish homes with children with and without atopic disease.

Low levels of endotoxin in dust from carpets, expressed as endotoxin units (EU) per mg dust, were associated with atopic disease in Sweden, but not in Estonia. The $10^{\text {th }}$, $25^{\text {th }}, 50^{\text {th }}, 75^{\text {th }}$ and $90^{\text {th }}$ percentiles are indicated, as well as outliers. 


\section{References}

1. Prescott SL, Macaubas C, Holt BJ, et al. Transplacental priming of the human immune system to environmental allergens: Universal skewing of initial T cell responses toward the Th2 cytokine profile. J Immunol 1998;160:4730-4737.

2. Yang LP, Byun DG, Demeure CE, Vezzio N, Delespesse G. Default development of cloned human naive CD4 T cells into interleukin-4- and interleukin-5-producing effector cells. Eur J Immunol 1995;25:3517-3520.

3. Adkins P, Bu YR, Guevara P. The generation of Th memory in neonates versus adults: Prolonged primary Th2 effector function and impaired development of Th1 memory effector function in murine neonates. J Immunol 2001;166:918-925.

4. Manetti R, Parronchi P, Giudizi MG, et al. Natural killer cell stimulatory factor (interleukin 12 [IL-12]) induces helper type 1 (Th1)-specific immune responses and inhibits the development of IL-4 producing Th cells. J Exp Med 1993;177:1199-1204.

5. Rogge L, D'Ambrosio D, Biffi M, et al. The role of Stat4 in species-specific regulation of Th cell development by type I IFNs. J Immunol 1998;161:6567-6574.

6. Burr M, Butland BK, King S, Vaughan-Williams E. Changes in asthma prevalence: Two surveys fifteen years apart. Arch Dis Childhood 1989;64:1452-1456.

7. Åberg N, Hesselmar B, Åberg B, Eriksson B. Increase of asthma, allergic rhinitis and eczema in Swedish schoolchildren between 1979 and 1991. Clin Exp Allergy 1995;25:815-819.

8. Butland BK, Strachan DP, Lewis S, Bynner J, Butler N, Britton J. Investigation into the increase in hay fever and eczema at age 16 observed between the 1958 and 1970 British birth cohorts. Br Med J 1997;315:717-721.

9. Holt PG. Environmental factors and primary T-cell sensitisation to inhalant allergens in infancy: Reappraisal of the role of infections and air pollution. Pediatr Allergy Immunol 1995;6:1-10.

10. von Mutius E, Fritzsch C, Weiland SK, Röll G, Magnussen H. Prevalence of asthma and allergic disorders among children in united Germany: A descriptive comparison. Br Med J 1992;305:1395-1399.

11. Björkstén B, Dumitrascu D, Foucard T, et al. Prevalence of childhood asthma, rhinitis and eczema in Scandinavia and Eastern Europe. Eur Respir J 1998;12:432-437.

12. Riikjärv MA, Annus T, Bråbäck L, Rahu K, Björkstén B. Similar prevalence of respiratory symptoms and atopy in Estonian schoolchildren with changing lifestyle over 4 yrs. Eur Respir J 2000;16:86-90.

13. Braun-Fahrländer C, Gassner M, Grize L, et al. Prevalence of hay fever and allergic sensitization in farmer's children and their peers living in the same rural community. Clin Exp Allergy $1999 ; 29: 28-34$.

14. Riedler J, Eder W, Oberfeld G, Schreuer M. Austrian children living on a farm have less hay fever, asthma and allergic sensitization. Clin Exp Allergy 2000;30:194-200.

15. Kilpeläinen M, Terho EO, Helenius H, Koskenvuo M. Farm environment in childhood prevents the development of allergies. Clin Exp Allergy 2000;30:201-208.

16. von Ehrenstein OS, von Mutius E, Illi S, Baumann L, Bohm O, von Kries R. Reduced risk of hay fever and asthma among children of farmers. Clin Exp Allergy 2000;30:187-193.

17. Ernst P, Cormier $\mathrm{Y}$. Relative scarcity of asthma and atopy among rural adolescents raised on a farm. Am J Respir Crit Care Med 2000;161:1563-1566. 
18. Riedler J, Braun-Fahrländer C, Eder W, et al. Exposure to farming in early life and development of asthma and allergy: A cross-sectional survey. Lancet 2001;358:1129-1133.

19. Verhasselt V, Buelens C, Willems F, De Groote D, Haeffner-Cavaillon N, Goldman M. Bacterial lipopolysaccharide stimulates the production of cytokines and the expression of costimulatory molecules by human peripheral blood dendritic cells: Evidence for a soluble CD14-dependent pathway. J Immunol 1997;158:2919-2925.

20. von Mutius E, Braun-Fahrländer C, Schierl R, et al. Exposure to endotoxin or other bacterial components might protect against the development of atopy. Clin Exp Allergy 2000;30:12301234.

21. Tulic MK, Wale JL, Holt PG, Sly PD. Modification of the inflammatory response to allergen challenge after exposure to bacterial lipopolysaccharide. Am J Respir Cell Mol Biol 2000;22:604612.

22. Bråbäck L, Breborowicz A, Julge $\mathrm{K}$, et al. Risk factors for respiratory symptoms and atopic sensitization among school children in the Baltic area. Arch Dis Childhood 1995;72:487-493.

23. Hesselmar B, Åberg N, Åberg B, Eriksson B, Björkstén B. Does early exposure to cat or dog protect against later allergy development? Clin Exp Allergy 1999;29:611-617.

24. Roost HP, Kunzli N, Schindler C, et al. Role of current and childhood exposure to cat and atopic sensitization. J Allergy Clin Immunol 1999;104:941-947.

25. Johnson CC, Ownby DR, Peterson EL. Pet ownership during infancy protects against allergic sensitisation. J Allergy Clin Immunol 2000;105:S80.

26. Gereda JE, Leung DYM, Thatayatikom A, et al. Relation between house-dust endotoxin exposure, type $1 \mathrm{~T}$ cell development, and allergen sensitisation in infants at high risk of asthma. Lancet 2000;355:1680-1683.

27. Gehring U, Bolte G, Borte M, et al. Exposure to endotoxin decreases the risk of atopic eczema in infancy: A cohort study. J Allergy Clin Immunol 2001;108:847-854.

28. Corinti S, Albanesi C, la Sala A, Pastore S, Girolomoni G. Regulatory activity of autocrine Il-10 on dendritic cell functions. J Immunol 2001;166:4312-4318.

29. Koulis A, Robinson DS. The anti-inflammatory effects of interleukin-10 in allergic disease. Clin Exp Allergy 2000;30:747-750.

30. Matricardi PM, Rosmini F, Riondino S, et al. Exposure to foodborne and orofecal microbes versus airborne viruses in relation to atopy and allergic asthma: Epidemiological study. Br Med J 2000;320:412-417.

31. Matricardi PM, Bonini S. High microbial turnover rate preventing atopy: A solution to inconsistencies impinging on the Hygiene hypothesis? Clin Exp Allergy 2000;30:1506-1510.

32. Eldridge MW, Peden DB. Allergen provocation augments endotoxin-induced nasal inflammation in subjects with atopic asthma. J Allergy Clin Immunol 2000;105:475-481. 
Fig 1

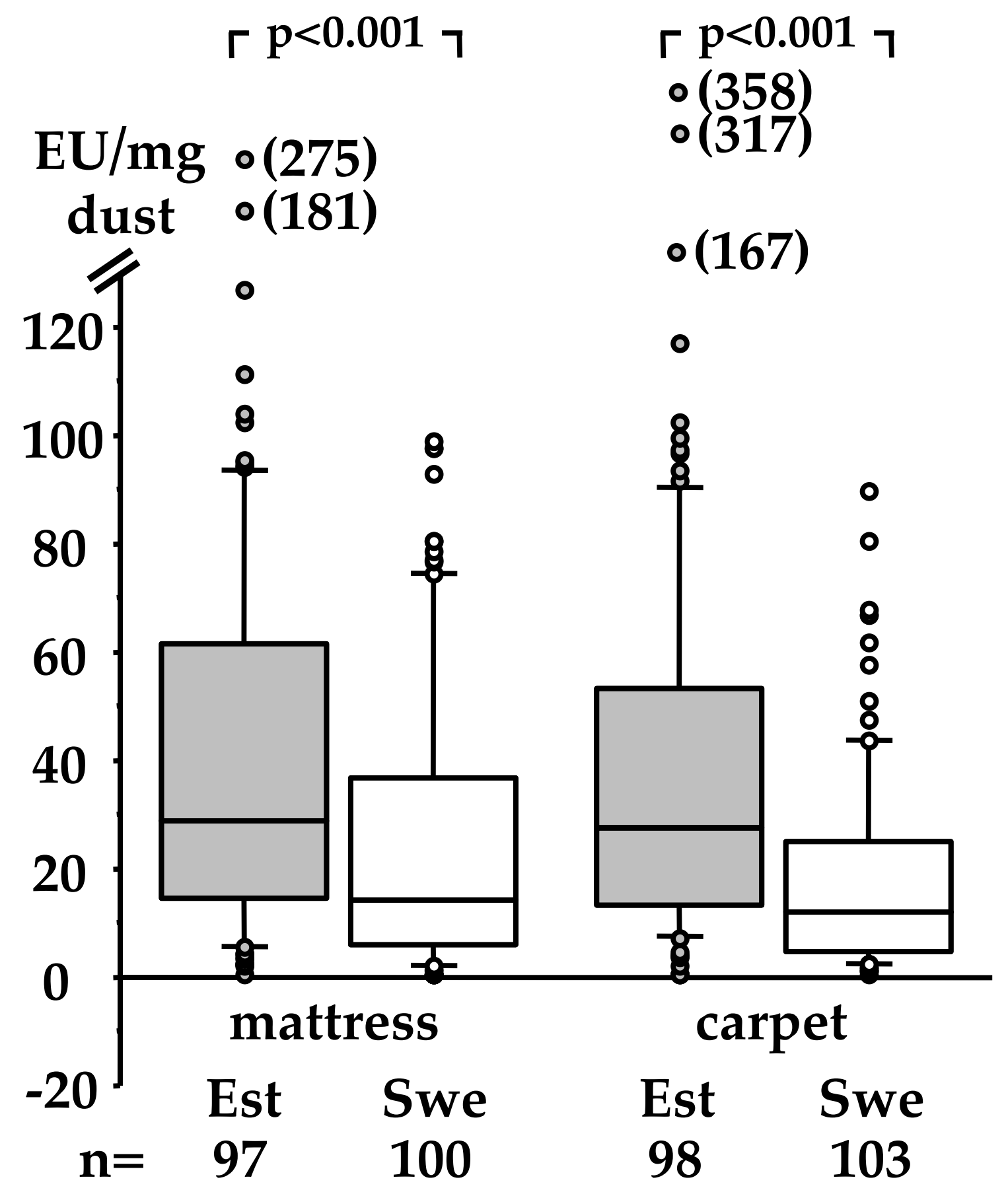


Fig 2a

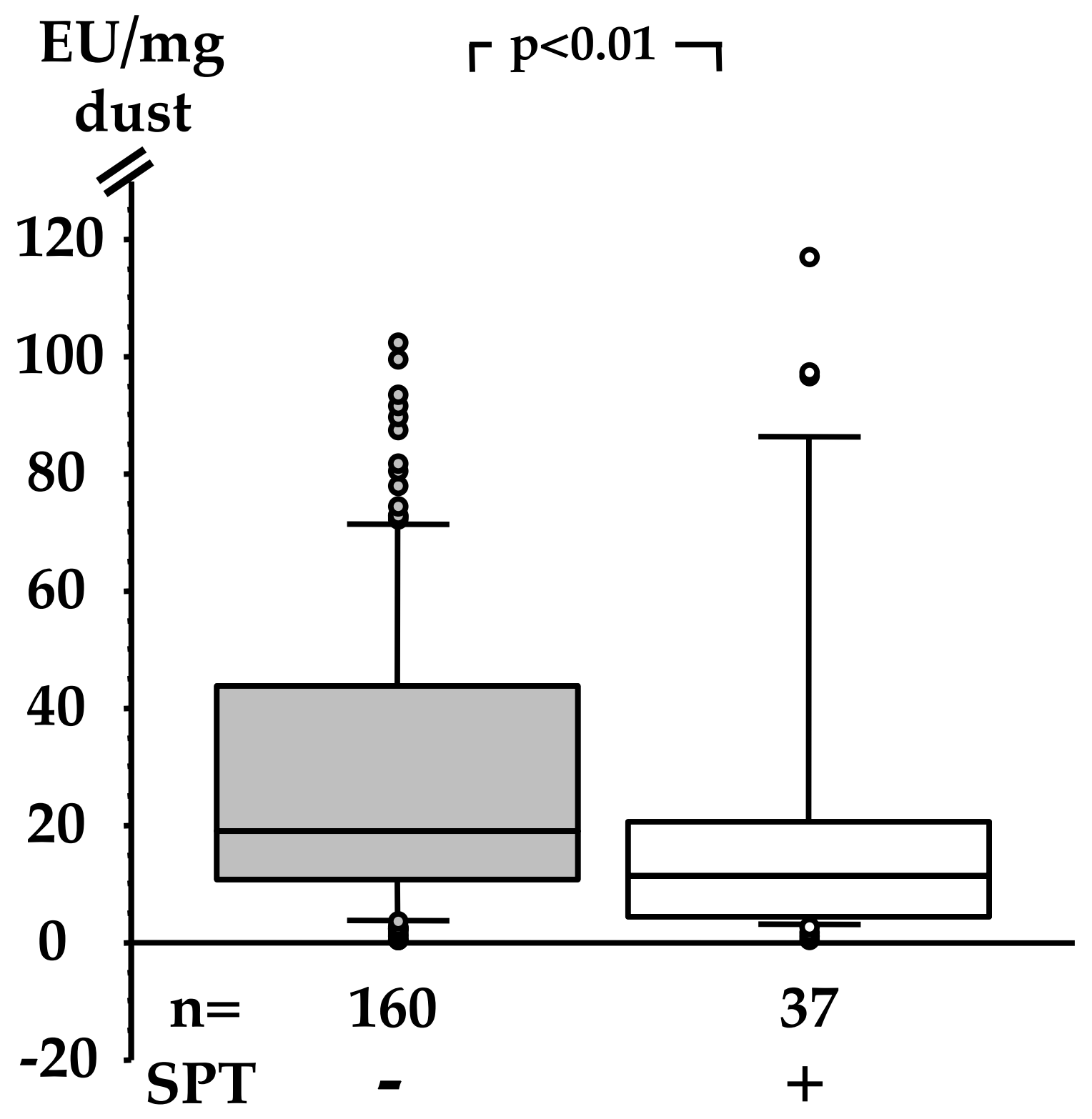


Fig $2 b$

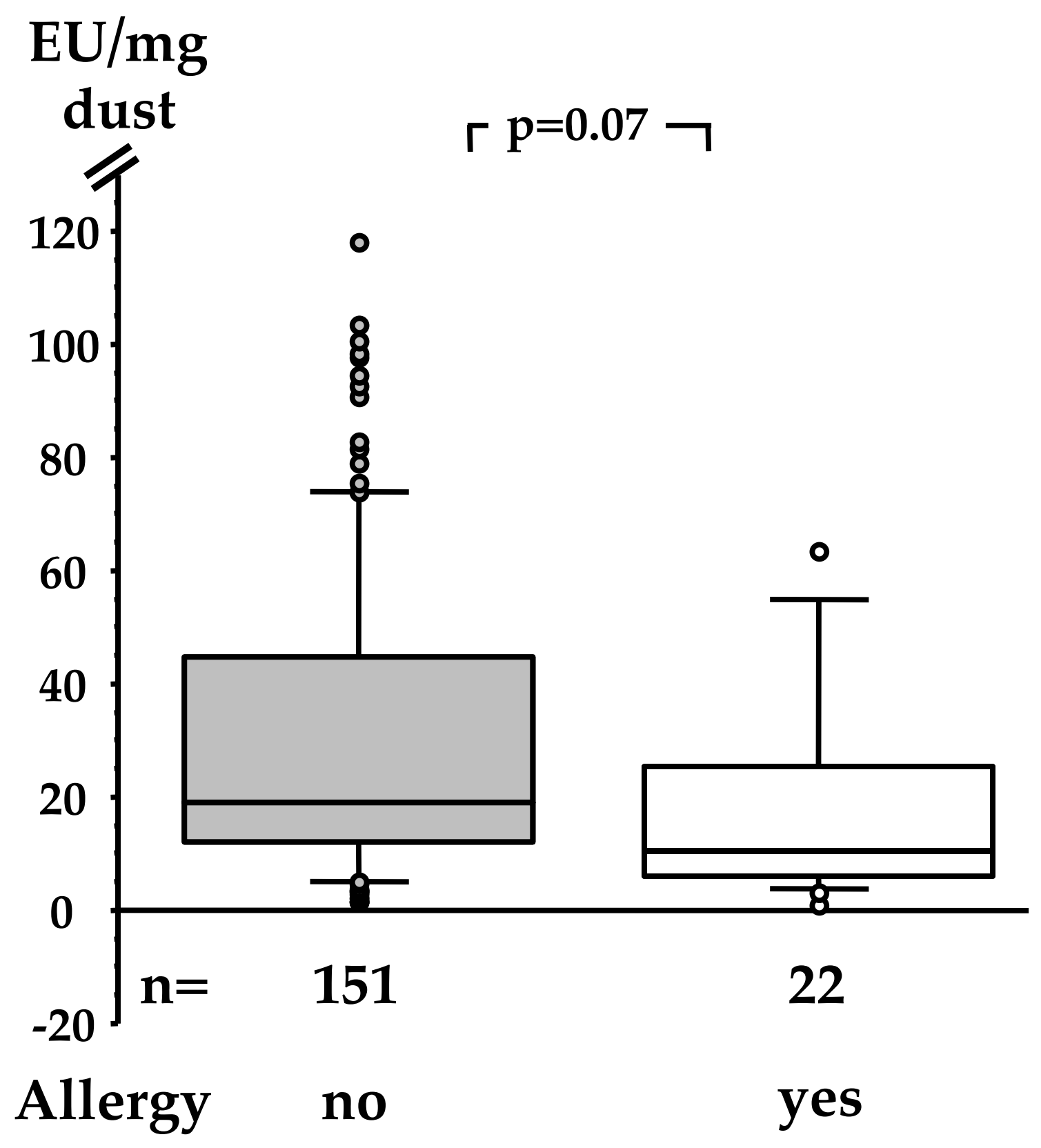


Fig 3

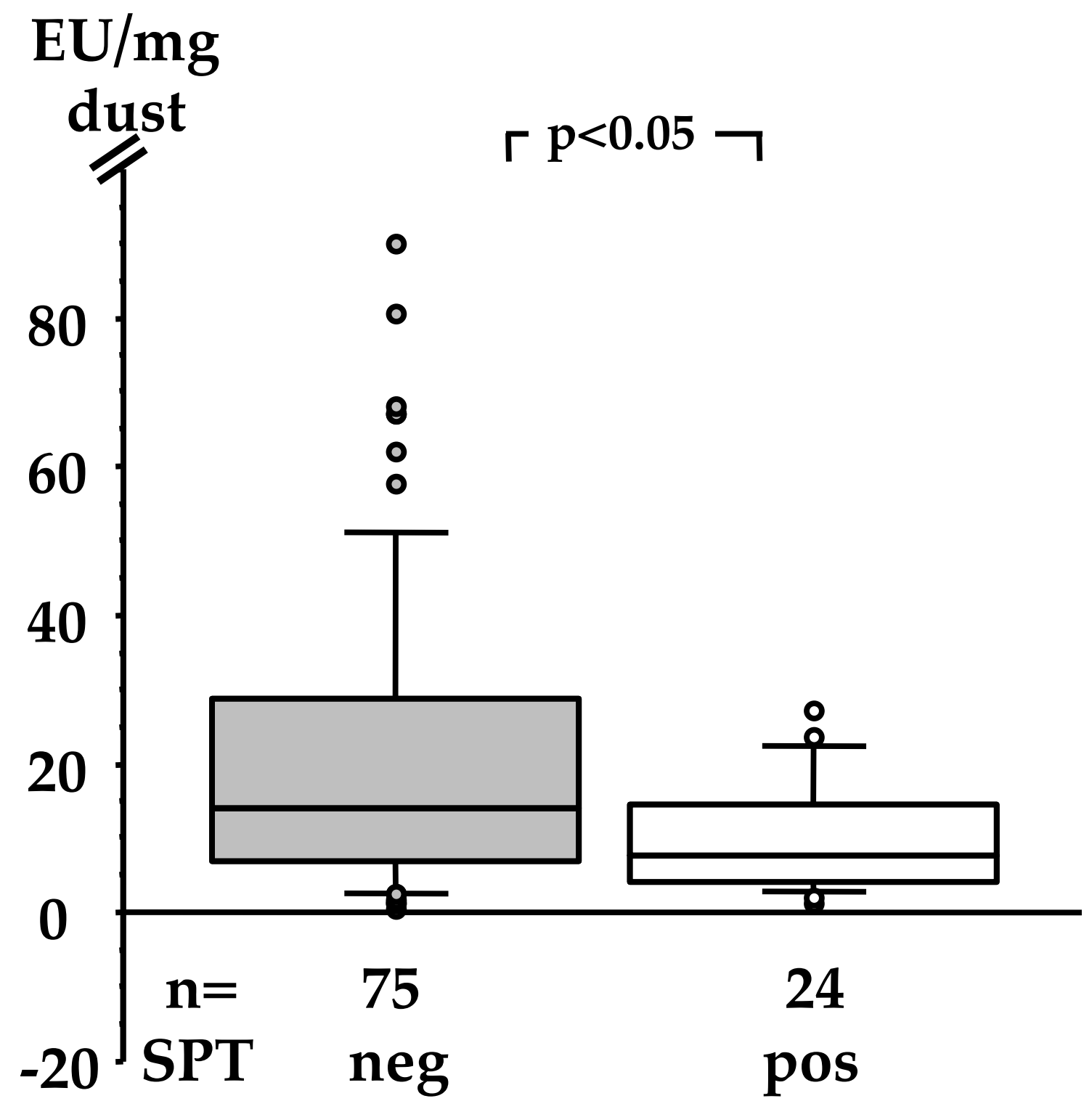


Fig $2 b$

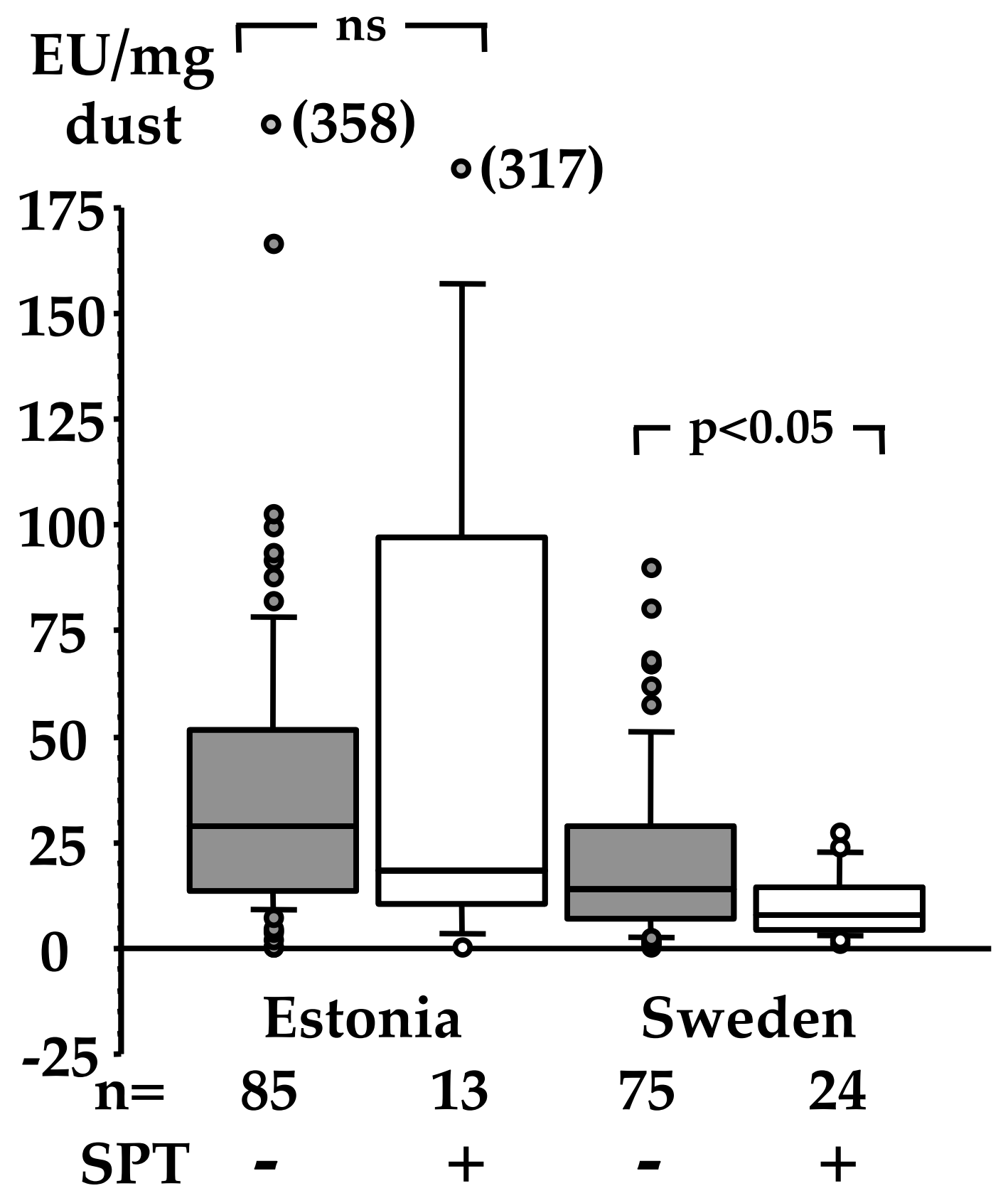

